\title{
La competencia extraterritorial de las municipalidades: el caso CARES
}

\author{
The extraterritorial jurisdiction of municipalities: The CARES case
}

\author{
Juan Andrés Encina Brevis (iD \\ Abogado, Chile
}

\begin{abstract}
RESUMEN Según la doctrina clásica, los municipios solo pueden actuar válidamente dentro de su territorio. Sin embargo, la Contraloría General de la República ha resuelto la validez de actuaciones en comunas distintas. El autor argumenta que existen tres tipos de actuaciones validadas: cuando existiere normativa especial, cuando las actuaciones no impliquen el desempeño de funciones de otras municipalidades u otros órganos del Estado, y cuando cumpla funciones municipales como la promoción del desarrollo comunitario. Uno de estos casos es revisado minuciosamente, sobre la instalación y administración de hogares estudiantiles fuera de la extensión de la comuna, en que el autor fuere su asesor legal.
\end{abstract}

PALABRAS CLAVE Municipalidades, territorio, comuna, competencia, hogares estudiantiles.

ABSTRACT According to Chile's classic doctrine municipalities only have jurisdiction within a given estate or county. Nonetheless, the Comptroller General of the Republic has resolved the validity of acts performed by municipalities outside their territorial boundaries. The author argues that there exist three types of acts that have been validated: when there is specific legislation on the subject, when the acts do not interfere with the jurisdiction of another municipality or of another administrative agency of government, and when the act is in accordance to the municipality's functions such as promoting the development of its very own local community. One of these cases is thoroughly reviewed, regarding the installation and administration of student housing facilities outside the municipality's domain, in which the author worked as the main legal advisor during the procedure.

KEYWORDS Municipalities, territory, county, jurisdiction, student housing. 


\section{Marco teórico: Concepto clásico de competencia}

\section{Introducción: Interpretación doctrinal clásica}

Como sabemos, el artículo 7 de la Constitución Política establece tres requisitos para que los órganos del Estado actúen de manera válida: la previa investidura regular de sus integrantes, dentro de su competencia y en la forma que prescriba la ley (Cea Egaña, 2008: 251). Respecto de este segundo requisito, en el caso de las municipalidades, la interpretación doctrinal y jurisprudencial clásica de la normativa del ramo es que su competencia está determinada exclusivamente por el elemento territorio, pudiendo solamente actuar válidamente dentro de su comuna. Así se desprendería de lo dispuesto expresamente en el inciso primero del artículo 118 de la Carta Fundamental, y del artículo 1 de la Ley Orgánica Constitucional de Municipalidades, que se refieren a la administración local.

A mayor abundamiento, el suscrito agrega que la lógica del sistema se comprende al analizar la totalidad del capítulo 14 de la Carta Fundamental, el cual crea los órganos cuya competencia se determina a través del elemento territorio. De este modo, dicho capítulo regula el gobierno y la Administración del Estado, mediante dividir el territorio de la República en regiones, provincias y comunas, las cuales son administradas respectivamente por el gobierno regional, delegaciones presidenciales provinciales y municipalidades (Constitución Política de la República de Chile, artículos 110 a 126).

En este sentido, el artículo 118 de la Constitución establece que la administración local de cada comuna o agrupación de comunas que determine la ley reside en una municipalidad (artículo 118, inciso primero), cuya finalidad es satisfacer las necesidades de la comunidad local y asegurar su participación en el progreso económico, social y cultural de la comuna (artículo 118, inciso cuarto).

A su vez, este último órgano es regulado por una ley especial, denominada Ley Orgánica Constitucional de Municipalidades, creada en virtud del mandato establecido por el artículo 118 inciso quinto de la Constitución. Este cuerpo legal repite la citada disposición en su artículo 1, y añade respecto a sus atribuciones privativas y funciones que ellas corresponderán «en el ámbito de su territorio» (Ley 18.695, artículos 3 y 4 ). ${ }^{1}$

Por tanto, una primera interpretación - siguiendo criterios literales y sistemáticos- es que la competencia municipal se funda exclusivamente en el elemento territorio, entendido como espacio físico o comuna. Esto es, el municipio únicamente puede actuar válidamente dentro de su comuna, pues éste es su territorio. Ésta es la interpretación seguida por la doctrina clásica en nuestro país, según la cual las municipalidades ejercen su potestad administrativa en este territorio determinado, denominado comuna, y es donde su autoridad tiene vigencia (Fernández Richard, 2007: 19).

1. Lo anterior es sin perjuicio de las excepciones expresamente previstas por la ley. 
En razón de esta interpretación literal, la doctrina nacional sobre el elemento territorio es muy limitada, por entenderse como tema zanjado. ${ }^{2}$

\section{Principal normativa general aplicable}

En primer lugar, ya en su primer capítulo, la Constitución Política de la República (sobre «Bases de la institucionalidad») establece en su artículo 3 que el Estado de Chile es unitario, que la administración del Estado será funcional y territorialmente descentralizada o desconcentrada en su caso, y que los órganos del Estado promoverán el fortalecimiento de la regionalización del país y el desarrollo equitativo y solidario entre las regiones, provincias y comunas del territorio adicional.

Agrega la Constitución en sus artículos 6 y 7 que, en lo atingente, los órganos del Estado deben someter su acción a la Constitución y a las normas dictadas conforme a ella, que para actuar válidamente se exigirá que actúen dentro de su competencia, y que ninguna magistratura, persona ni grupo de personas pueden atribuirse, ni aun a pretexto de circunstancias extraordinarias, otra autoridad o derechos que los que expresamente se les hayan conferido en virtud de la Constitución o las leyes.

Respecto a este órgano, en su capítulo 14 («Sobre gobierno y administración interior del Estado»), dispone en su artículo 110 que el territorio de la República se divide en regiones y éstas en provincias, las cuales se dividirán en comunas para efectos de la administración local. El artículo 118 prevé que la administración local de cada comuna o agrupación de comunas reside en una municipalidad, definiéndolas en su inciso cuarto como corporaciones autónomas de derecho público, con personalidad jurídica y patrimonio propio, cuya finalidad es satisfacer las necesidades de la comunidad local y asegurar su participación en el progreso económico, social y cultural de la comuna. Añade su artículo 123 que la ley establecerá fórmulas de coordinación para la administración de los municipios respecto a problemas que les sean comunes, y el artículo 126 que la ley determinará la forma de resolver las cuestiones de competencia que pudieren suscitarse.

En segundo lugar, en nuestro derecho existe una ley especial que regula a este órgano territorial, denominada Ley Orgánica Constitucional de Municipalidades. En cuanto a las principales normas concretas, sus artículos 3 y 4 disponen que corresponderá a las municipalidades, en el ámbito de su territorio, una serie de funciones. Destaca como función privativa del municipio la contenida en la letra c) del artículo 3, referida a la promoción del desarrollo comunitario. Añade su artículo 129 que una o más municipalidades podrán constituir o participar en corporaciones o fundaciones de derecho

2. También en derecho comparado se ha entendido de esta manera. A modo de ejemplo, en García de Enterría y Fernández (2002: 380), sobre el derecho español se ha escrito lo siguiente: «El poder de los entes territoriales se entiende sobre la totalidad de la población existente en su territorio; en cambio, los entes no territoriales actúan con poderes únicamente en relación con determinados habitantes. Por ser entes territoriales, el municipio tiene ciertas finalidades universales, mientras que los entes no territoriales tienen especialidad». 
privado, sin fines de lucro, destinadas a la promoción y difusión del arte, la cultura y el deporte, o el fomento de obras de desarrollo comunal y productivo.

A su vez, se refiere extensamente a la coordinación, a las asociaciones y a los convenios entre municipalidades, en sus artículos 10, 18 y 138. Finalmente, su artículo 2 transitorio establece la regulación de las cuestiones de competencia.

\section{Sentencia del Tribunal Constitucional, rol 1.669-2010, del 15 de marzo de 2012}

En una de sus sentencias más destacadas, el Tribunal Constitucional chileno se pronunció, con afán definitivo, sobre la posición de las municipalidades en la administración nacional (Zúñiga Urbina, 2012: 405). Dicha sentencia fue dictada en el procedimiento rol 1.669-2010, del 15 de marzo de 2012, sobre requerimiento de inaplicabilidad por inconstitucionalidad, de los artículos 5 letra c) y 12 de la Ley Orgánica de Municipalidades, y los artículos 15, 124 y 221 de la Ley General de Servicios Eléctricos.

En resumidas cuentas, sobre el particular el Tribunal Constitucional se refirió al elemento territorio del municipio de la siguiente forma:

Considerando decimoctavo: Los municipios son más que órganos descentralizados territorialmente. Así los definía el Decreto Ley 1.289, al señalar que eran instituciones de derecho público, funcional y territorialmente descentralizadas. Con la Constitución de 1980, son órganos autónomos. Ahora bien, para Verdugo Marinkovic, Pfeffer Urquiaga y Nogueira Alcalá (1999: 397), la autonomía del municipio consiste en que se trata de «entes jurídicos que disponen de la capacidad de autoadministrarse en el ámbito de sus atribuciones con independencia del nivel administrativo regional y nacional». Para Pantoja, son «órganos acentralizados», pues no dependen ni se relacionan con el gobierno por un vínculo de supervigilancia, encontrándose en un plano de extraordinaria independencia respecto de éste (Pantoja Bauzá, 1998: 312). Producto de la autonomía decisoria que tienen en el ámbito de su competencia, por de pronto, no hay normas que permitan vetar o suspender decisiones que adopten sus autoridades por parte de las autoridades administrativas nacionales. En este sentido, deciden de manera definitiva, sin que sus opciones puedan ser sustituidas o mediatizadas jurídicamente por actos del poder central. Tienen, por tanto, una capacidad de acción de discrecionalidad de configuración, muy superior a la de los servicios públicos descentralizados. Enseguida, el poder central no puede pedir la remoción de su autoridad superior, es decir del alcalde; ello cuando procede y conforme al procedimiento que regula la ley, sólo se activa por los propios concejales (artículo 6o, Ley Orgánica Constitucional de Municipalidades). Finalmente, una vez que entre en vigencia la facultad que les otorga el artículo 121 de la Constitución, podrán crear o suprimir empleos, fijar remuneraciones y establecer órganos o unidades, sin intervención del legislador nacional, como sucede respecto de los servicios públicos (artículo 65, inciso cuarto de la Constitución). Sin embargo, dicha autonomía no es absoluta. Por una parte, porque está limitada «por las facultades que en relación a ella pueden ejercer el legislador, la autoridad administrativa, la judicial, la Contraloría General de la República» (Silva Bascuñán, 2004: 130-131). Es una autonomía para que se «autorregulen dentro del mar- 
co de la función y las atribuciones que les fijan la Constitución y las leyes». Por la otra, la autonomía que tienen es administrativa, pues su función es la de «administración local de cada comuna o agrupación de comunas que determine la ley» (artículo 118 de la Constitución).

Considerando decimonoveno: Los municipios tienen un espacio físico donde operan y ejercen sus funciones: la comuna. Esta área geográfica es un elemento constitutivo esencial del municipio, sin el cual este no existe. Para los entes no territoriales, en cambio, el territorio es sólo el espacio físico en que desarrollan sus actividades. De ahí que el poder de los entes territoriales se entienda sobre la totalidad de la población existente en su territorio; en cambio, los entes no territoriales actúan con sus poderes únicamente en relación con determinados habitantes. Asimismo, casi nada escapa a lo que suceda a los habitantes de la comuna. El municipio tiene ciertas finalidades universales, mientras que los entes no territoriales tienen especialidad (García de Enterría y Fernández, 2002: 380). Esto último nos pone en contacto con el elemento final de los municipios que queremos destacar. La Constitución señala que los municipios tienen básicamente tres finalidades. La primera es «satisfacer las necesidades de la comunidad local»; la segunda, «asegurar su participación en el progreso económico, social y cultural de la comuna»; y la tercera, «ejercer la administración local».

Considerando vigésimo primero: Que, para cumplir estas tareas, el ordenamiento jurídico entrega al municipio potestades. Éstas guardan relación con la entidad de las funciones que a la institución se le encarga atender. [...] El rol de los municipios es «la administración local» (artículo 118 de la Constitución), es decir, «la resolución de aquellos asuntos que tienen relación con los intereses de una porción limitada de nuestro territorio» (Bernaschina González, 1952: 17). [...] Los municipios tienen, entonces, autonomía para autodeterminarse, en conformidad a la Constitución y a la ley, en asuntos de claro interés local, eligiendo entre diferentes opciones o estrategias. Tienen, por tanto, una discrecionalidad no sólo aplicativa sino innovadora o de conformación en las tareas que se le encomiendan. La Constitución les asigna la función de procurar el «progreso económico, social y cultural de la comuna». Por tanto, deben poder actuar, en ámbitos propios, sin mandatos ni controles de los entes nacionales.

\section{Jurisprudencia administrativa: Concepto actual de competencia}

\section{Importancia de la jurisprudencia administrativa sobre el particular}

La citada sentencia del Tribunal Constitucional es la única dictada en materia judicial que se ha referido a la competencia territorial de las municipalidades en Chile. De este modo, la Corte Suprema no se ha pronunciado sobre el particular, y el mayor desarrollo jurisprudencial ha sido creado por la Contraloría General de la República. En mérito de ello, el presente artículo se referirá en lo sucesivo a la opinión jurídica del órgano de control.

Dicho lo anterior, si bien en principio la competencia de las municipalidades pareciere siempre limitarse a la administración de su propia comuna, dada la interpretación literal de la normativa de carácter general, en ciertos casos la Contraloría General de la 
República ha permitido que las municipalidades puedan actuar válidamente fuera de su territorio. Por tanto, en nuestro derecho, el territorio comunal ya no es únicamente el único factor de competencia.

De este modo, la posición doctrinal clásica - y hasta ahora unánime- no siempre es acogida por la jurisprudencia administrativa, sino que la resolución depende de los antecedentes de cada caso concreto. Y, adelantando desde ya, en la mayoría de los casos más recientes no fue acogida esta posición clásica descrita hasta este punto.

\section{Dictámenes de Contraloría General de la República en general}

A efectos de analizar lo resuelto por el órgano de control sobre el particular, a continuación, la tabla 1 lista todos los asuntos en que se ha discutido la competencia extraterritorial de las municipalidades ante la Contraloría General de la República. De este modo, tenemos que Contraloría General históricamente ha tenido las siguientes posiciones respecto de la competencia de las municipalidades fuera de su territorio:

- Rechazar la facultad extraterritorial, mayormente en casos más antiguos.

- Aceptar la facultad extraterritorial, especialmente en casos más recientes.

Tabla 1. Jurisprudencia administrativa sobre la facultad extraterritorial de las competencias municipales

\begin{tabular}{|lll|}
\hline Dictamen & Fecha de dictación & Resolución \\
\hline $27.208 / 1989$ & 9 de octubre de 1989 & Rechazado \\
\hline $3.289 / 1994$ & 28 de enero de 1994 & Rechazado \\
\hline $38.520 / 2000$ & 10 de octubre de 2000 & Acogido \\
\hline $51.620 / 2005$ & 2 de noviembre de 2005 & Acogido \\
\hline $39.282 / 2008$ & 20 de agosto de 2008 & Rechazado \\
\hline $27.271 / 2009$ & 26 de mayo de 2009 & Rechazado \\
\hline $2.891 / 2010$ & 18 de enero de 2010 & Rechazado \\
\hline $76.276 / 2012$ & 7 de diciembre de 2012 & Rechazado \\
\hline $66.754 / 2013$ & 16 de octubre de 2013 & Acogido \\
\hline $3.000 / 2017$ & 7 de enero de 2017 & Acogido \\
\hline $4.491 / 2017$ & 7 de febrero de 2017 & Rechazado \\
\hline $22.772 / 2017$ & 21 de junio de 2017 & Acogido \\
\hline
\end{tabular}

Fuente: Elaboración propia. 


\section{Dictámenes en contra de la competencia extraterritorial de las municipalidades}

La Contraloría General de la República, mayoritariamente, ha resuelto solo validar las actuaciones municipales que hayan sido hechas dentro de su territorio jurisdiccional respectivo, según se desprende de la tabla 2.

Tabla 2. Jurisprudencia administrativa que rechazan las actuaciones extraterritoriales de las municipalidades

\begin{tabular}{|ll|}
\hline Dictamen & Fecha de dictación \\
\hline $27.208 / 1989$ & 9 de octubre de 1989 \\
$3.289 / 1994$ & 28 de enero de 1994 \\
$39.282 / 2008$ & 20 de agosto de 2008 \\
$27.271 / 2009$ & 26 de mayo de 2009 \\
\hline $2.891 / 2010$ & 18 de enero de 2010 \\
$76.276 / 2012$ & 7 de diciembre de 2012 \\
$4.491 / 2017$ & 7 de febrero de 2017 \\
\hline
\end{tabular}

Fuente: Elaboración propia.

Como resumen, indicaremos los dictámenes que han rechazado dicha facultad y los argumentos que ha esgrimido Contraloría General para el rechazo.

\section{Dictamen 27.208/1989}

Es improcedente la instalación de puestos para otorgar permisos de circulación en territorios jurisdiccionales de otras comunas, por cuanto los municipios están destinados a satisfacer las necesidades solo de la comunidad local, dentro de su territorio jurisdiccional. Las municipalidades no tienen otras atribuciones o derechos que aquéllos que expresamente les hayan conferido las leyes, en virtud del principio de especialidad. Además, las entidades edilicias no pueden extender su funcionamiento más allá del ámbito jurisdiccional fijado por la ley, ya que de lo contrario se invadiría el campo de atribuciones de otros municipios al actuar en su territorio.

\section{Dictamen 3.289/1994}

Las municipalidades no pueden utilizar inmuebles que poseen en comunas distintas para ejercer en ellos funciones, atribuciones o potestades públicas o de gestión administrativa, las que deben hacerse dentro del territorio de sus respectivas jurisdicciones. Según el artículo 107 de la Constitución y el artículo 1 de la Ley 18.695, es el elemento territorio es el que marca la competencia de cada uno de los municipios que tienen a su cargo la administración local de una comuna (principio de legalidad). 
No obstante, un municipio sí puede ser titular de uno o más inmuebles ubicados en una comuna distinta, porque la adquisición de las mismas se rige por las normas del derecho común, de conformidad con el artículo 29 de la Ley 18.695. Estos bienes de su propiedad no pueden utilizarse para ejercer sus atribuciones públicas en localidades distintas, sino únicamente ejercer los atributos del dominio.

\section{Dictamen 39.282/2008}

No corresponde que las municipalidades puedan actuar fuera de su territorio como producto de catástrofes, en este caso la catástrofe producida por la erupción del volcán Chaitén. Las municipalidades únicamente pueden desarrollar funciones relacionadas con la prevención de riesgos dentro de su comuna respectiva, y solo de forma excepcional en los casos en que la ley lo permita podrán actuar de manera válida fuera de los límites comunales (cita el Dictamen de la Contraloría General de la República 51.620, de 2005).

Agrega que, si bien no fue aplicado en el presente asunto, la Ley 16.282 permite al presidente de la República flexibilizar las disposiciones orgánicas de las entidades que indica el artículo 3 de dicha norma, con el objetivo de auxiliar a los damnificados por la catástrofe. Las municipalidades forman parte del Plan Nacional de Protección Civil, aprobado por el Decreto Supremo 156, de 2002, del Ministerio del Interior, mediante el cual dicho ministerio es el encargado de planificar, coordinar y ejecutar las actividades destinadas a prevenir y solucionar problemas derivados de sismos y catástrofes. Las municipalidades no actúan de manera aislada y con plena autonomía.

\section{Dictamen 27.271/2009}

Las municipalidades solo tienen competencia para participar como entidades de gestión inmobiliaria social en el ámbito de su territorio comunal, por lo que no pueden construir viviendas sociales en otra comuna. Según lo precisado por el dictamen $51.620 / 2005$, el elemento territorial marca la competencia de cada una de las municipalidades, de manera que las funciones y atribuciones que el ordenamiento jurídico les confiere han sido concebidas para que sean ejercidas por cada una de dichas entidades solo dentro de sus respectivos ámbitos territoriales, esto es, en las comunas que legalmente les corresponde administrar. Atendido el principio de legalidad, consagrado en los artículos 6 y 7 de la Carta Suprema, y 2 de la Ley 18.575, que obliga a los órganos de la Administración del Estado a actuar con sujeción a la Constitución y las leyes, dentro de su competencia y sin más atribuciones que las que expresamente les confiera el ordenamiento jurídico, no resulta procedente que un municipio extienda su funcionamiento fuera de la respectiva comuna.

\section{Dictamen 2.891/2010}

El actuar de las municipalidades como organismos técnicos de capacitación debe circunscribirse dentro del ámbito de su territorio comunal. Las actividades que el munici- 
pio ejecuta en esta calidad corresponden al ejercicio de la función municipal establecida en el artículo 4 letra d) de la Ley 18.695, por lo cual corresponde que esta actividad y función se haga solo dentro de su comuna (cita el Dictamen de la Contraloría General de la República 51.620, de 2005).

\section{Dictamen $76.276 / 2012$}

Los municipios deben actuar coordinadamente frente a solicitudes de fusión de terrenos contiguos ubicados en áreas urbanas de comunas distintas. En caso contrario dicho asunto será considerado una cuestión de competencia que deberá ser resuelta por el gobernador respectivo, según lo previsto en el artículo 2 transitorio de la Ley 18.695 (cita el Dictamen de la Contraloría General de la República 51.620, de 2005).

Sin embargo, en la parte considerativa agrega que:

No obstante, es del caso apuntar que las aludidas limitaciones (sobre territorio) no pueden significar que los municipios dejen de cumplir sus funciones y su finalidad última, que no es otra que la satisfacción de las necesidades de la comunidad local en forma continua y permanente, con sujeción a lo preceptuado en los artículos 118 de la Constitución Política de la República y 1, inciso segundo, de la citada Ley 18.695.

\section{Dictamen 4.491/2017}

Las farmacias municipales no pueden expedir medicamentos a vecinos de otras comunas. Citando su definición legal, argumenta que las municipalidades son corporaciones autónomas de derecho público, con personalidad jurídica y patrimonio único propio, cuya finalidad es satisfacer las necesidades de la comunidad local y asegurar su participación en el progreso económico, social y cultural de la comuna; dando a entender que únicamente puede favorecer a su comunidad local (elemento territorio y domicilio).

Precisa que existe la posibilidad de suscribir un convenio con otra municipalidad, con la finalidad de administrar conjuntamente la farmacia respectiva, cumpliendo con los requisitos de la Ley 19.378 .

\section{Dictámenes a favor de la competencia extraterritorial de las municipalidades}

A su vez, la Contraloría General ha resuelto validar actuaciones municipales hechas fuera de su territorio, destacando principalmente que ésta es la tesis seguida con mayor frecuencia en sus dictámenes más recientes.

\section{Dictamen $38.520 / 2000$}

La expresión «en el ámbito de su territorio» contenida en los artículos 3 y 4 de la Ley 18.695 debe entenderse en el sentido de que resulta procedente que una entidad edilicia excepcionalmente pueda otorgar subvenciones y aportes específicos a personas jurídi- 
Tabla 3. Jurisprudencia administrativa que validan la competencia extraterritorial de las municipalidades

\begin{tabular}{|ll|}
\hline Dictamen & Fecha de dictación \\
\hline $38.520 / 2000$ & 10 de octubre de 2000 \\
\hline $51.620 / 2005$ & 2 de noviembre de 2005 \\
$66.754 / 2013$ & 16 de octubre de 2013 \\
$3.000 / 2017$ & 7 de enero de 2017 \\
\hline $22.772 / 2017$ & 21 de junio de 2017 \\
\hline
\end{tabular}

Fuente: Elaboración propia.

cas de carácter público o privado, sin fines de lucro, que colaboren de manera directa en el cumplimiento de sus funciones (Ley 18.695, artículo 5, letra g), y aun en el caso de que sus acciones se radiquen en otro territorio comunal.

Para llegar a esta conclusión, Contraloría argumenta que la competencia de las municipalidades está determinada por su materia y por su territorio. Es decir, en este dictamen agrega el elemento materia, por cuanto antes solo considerada el elemento territorio. Expone que por materia se entiende sus funciones y atribuciones a que se encuentran abocadas las municipalidades a fin de dar cumplimiento a sus objetivos, $y$ por territorio el ámbito especial dentro del cual cada municipio ejerce sus funciones y atribuciones.

Agrega que de conformidad con los artículos 3, 4, 5 letra g) y 22 letra c), todos de la Ley 18.695, para cumplir con estas funciones y atribuciones (materia), las municipalidades pueden contribuir a instituciones sin fines de lucro y tener una Unidad de Desarrollo Comunitario, las cuales están facultadas por ley para administrar y ejecutar programas sociales y culturales básicos. Luego, estas instituciones podrán ejecutar «actividades destinadas a fomentar, entre otras, el deporte, la recreación, el turismo, la educación y la cultura, en beneficio de los habitantes de la comuna, aun cuando las acciones que los favorezcan se radiquen en otro territorio comunal».

En concreto y explicando el presente dictamen más allá de lo literal de lo resuelto, el programa en cuestión trata sobre que la Unidad de Desarrollo Comunitario de la Municipalidad de Concepción ejecute un plan de fortalecimiento de los hogares de ancianos y grupos juveniles o infantiles de la comuna, y que dentro de tales planes se hagan viajes a museos en Santiago o ir a distintas comunas para que sus habitantes puedan conocer el mar y la nieve, ello en cumplimiento de la ejecución de acciones relacionadas con el fomento de la educación, la cultura y la recreación (funciones y atribuciones municipales). Por tanto, en este caso, Contraloría decidió que el elemento materia le otorga competencia al municipio para así poder actuar en comunas distintas de la suya propia, puesto que está beneficiando a sus propios habitantes y por ende su actuar en otras localidades logra favorecer a su propia comuna. 


\section{Dictamen 51.620/2005}

Contraloría Regional deberá examinar si la actuación de un municipio se ha ajustado a derecho, sobre la posibilidad de contratar personas extranjeras, puesto que la validez de ella depende de las circunstancias del caso. El caso concreto se refiere a que la $\mathrm{Mu}$ nicipalidad de Coquimbo, sin convenio internacional alguno, instalara en la ciudad argentina de San Juan una oficina denominada «Casa Chile-Argentina», contratando tres personas de esa nacionalidad para atenderla. Sin embargo, la Contraloría Regional de Coquimbo solicitó un pronunciamiento sobre el particular.

La Contraloría General, en primer lugar, consideró un argumento que es reiteradamente citado en posteriores dictámenes:

Como cuestión previa, debe recordarse que según lo disponen los artículos 118 de la Constitución Política y 1, 4 y 63, letra i), de la Ley 18.695, la administración local de cada comuna o agrupación de comunas que determine la ley reside en una municipalidad y su finalidad es satisfacer las necesidades de la comunidad local y asegurar su participación en el progreso económico, social y cultural de la comuna, por lo que sus actos deben tender al adecuado cumplimiento de las funciones que les corresponda desarrollar en el ámbito de su territorio. De la normativa reseñada es posible advertir que el elemento territorial marca la competencia de cada una de las municipalidades, de manera tal que las funciones y atribuciones que el ordenamiento jurídico les confiere, han sido concebidas para que sean ejercidas por cada una de dichas entidades sólo dentro de sus respectivos ámbitos territoriales, esto es, en las comunas que legalmente le corresponde administrar (aplica criterio contenido en los dictámenes 27.208, de 1989 y 3.289 , de 1994, entre otros). Así, atendido el principio de legalidad, consagrado en los artículos 6 y 7 de la Carta Suprema y 2 de Ley 18.575, que obliga a los órganos de la Administración del Estado a actuar con sujeción a la Constitución y las leyes, dentro de su competencia y sin más atribuciones que las que expresamente les confiera el ordenamiento jurídico, no resulta procedente que un municipio extienda su funcionamiento fuera de la respectiva comuna, a través de la instalación de una oficina municipal al margen de los límites comunales.

En segundo lugar, prosigue su argumentación agregando dos posibilidades para que las municipalidades puedan actuar fuera de su territorio. Estas son:

Lo anterior no significa que las municipalidades no puedan actuar fuera de los límites de la comuna e incluso adquirir bienes, muebles e inmuebles, ubicados fuera de ella, en la medida en que estas actuaciones no impliquen el desempeño de funciones o potestades propias de su naturaleza de organismo público en otras comunas (aplica criterio contenido en el Dictamen 3.289, de 1994).

Asimismo, y acorde lo reconoce la jurisprudencia administrativa citada, las municipalidades pueden, en el marco de sus atribuciones y con arreglo a lo dispuesto en los artículos 8 y 63, letra ii), de la Ley 18.695, suscribir convenios cuyos efectos se extiendan más allá del respectivo territorio comunal, sin embargo, en tal caso, se requiere 
que el acto así celebrado redunde en beneficio de la respectiva comuna y contribuya al cumplimiento de las funciones municipales.

En tercer y último lugar, se refiere a la posibilidad de que una municipalidad pueda contratar personal extranjero, señalando que, por regla general, para formar parte de la dotación municipal se requiere nacionalidad chilena, pero que existen excepciones (Leyes 19.070 y 19.378). También considera la posibilidad de contratación a honorarios, que permite la contratación de extranjeros con el título correspondiente a la especialidad que se requiera (Ley 18.883). Por esta razón, Contraloría General resuelve que la resolución concreta deberá ser tomada por Contraloría Regional, puesto que depende del caso concreto en cuestión.

\section{Dictamen 66.754/2013}

Las municipalidades tienen competencia para instalar y administrar hogares estudiantiles fuera de la comuna, en virtud de que refuerza las funciones municipales - desarrollo comunitario, asistencia social, educación- y beneficia directamente a la población del territorio del municipio (cita el Dictamen de la Contraloría General de la República 51.620, de 2005).

Fundado en los artículos 1 inciso cuarto y 1910 de la Constitución Política, como también en los artículos 3 letra c) y 4 letras a) y e) de la Ley 18.695, resuelve que un programa ejecutado fuera de la comuna busca precisamente prestar asistencia social a familias de escasos recursos y propender al desarrollo educacional de la población de dicha comuna, por lo cual este programa contribuye a crear condiciones que permitan a sus habitantes la mayor realización espiritual y material posible. Esto es, el elemento materia - funciones y atribuciones municipales que benefician a los habitantes de su comunidad- extiende las facultades de los municipios, por sobre el mero elemento territorio.

Este dictamen se analizará con más detalle en la tercera parte de este artículo.

\section{Dictamen 3.00o/2017}

Las municipalidades se encuentran facultadas, de forma excepcional, para prestar su colaboración y auxilio ante situaciones de catástrofe ocurridas fuera de su ámbito de competencia territorial.

En primer lugar, se funda en la orgánica constitucional y administrativa, citando el principio de servicialidad establecido en el artículo 1 de la Constitución Política, en lo dispuesto en su artículo 118, por cuanto en la propia definición de municipalidades se establece que su finalidad es satisfacer las necesidades de la comunidad local; y en el principio de coordinación administrativa contenido en los artículos 3 y 5 de la Ley 18.575. En segundo lugar, se funda la normativa municipal, establecida en el artículo 4 letra i) de la Ley 18.695, que faculta a los entes edilicios a ejercer funciones relacionadas con la prevención de riesgos y la prestación de auxilio en situaciones de emergencia o 
catástrofes. En tercer lugar, se refiere a la normativa especial, contenida en el Decreto 104 de 1977, del Ministerio del Interior, el cual dispone que dicha Secretaría de Estado tendrá a su cargo la planificación y coordinación de la atención de sismos y catástrofes; y en el Decreto Ley 369 de 1974, que crea la Oficina Nacional de Emergencias (Onemi).

Para este actuar fuera de su territorio, Contraloría General exige tres condiciones. Primero, que la zona donde se produjo o se está produciendo la catástrofe haya sido declarada como tal por el Ministerio del Interior y Seguridad Pública. Segundo, que los municipios estimen que se justifica la intervención, atendida la magnitud de la emergencia y los daños de consideración generados o que podrían generarse. Tercero, que las entidades edilicias que resuelvan prestar su colaboración coordinen su acción con el referido ministerio, a través de la Onemi, sin perjuicio del deber de actuar en coordinación con los intendentes, gobernadores y gobiernos regionales, en virtud de la Ley 19.175, como también de lo que pueda establecerse en el evento de decretarse estado de excepción constitucional o de designación de la autoridad responsable que se efectúe en el decreto que declara zona afectada por catástrofe.

\section{Dictamen 22.772/2017}

En lo atingente, la Contraloría Regional debió resolver sobre la validez de que una funcionaria pueda ejercer labores en un lugar distinto a la municipalidad, basado en los antecedentes específicos del caso.

Sobre el particular, Contraloría General señaló expresamente que, si bien el territorio marca el límite de la competencia de cada municipalidad, lo anterior no significa que las entidades edilicias estén impedidas de actuar fuera de los límites de la comuna, en la medida en que estas actuaciones no impliquen el desempeño de funciones o potestades propias de su naturaleza de organismo público en otras comunas (cita el Dictamen de la Contraloría General de la República 51.620, de 2005 y el Dictamen 66.754, de 2013).

\section{Comentarios sobre la jurisprudencia administrativa}

En resumidas cuentas, el órgano de control ha tenido dos posiciones respecto de que las municipalidades puedan actuar válidamente fuera de su territorio: rechazarla y aceptarla.

De este modo, tenemos que, si bien para la doctrina nacional a la fecha y en una primera revisión a la normativa aplicable la conclusión es que las municipalidades únicamente pueden actuar dentro de su territorio, al continuar la lectura la interpretación no es tan clara como pareciere, puesto que Contraloría General ha resuelto en contrario en diversas ocasiones. Sin embargo, no podemos dejar de considerar que en su totalidad la mayoría de los dictámenes ha rechazado esta potestad, mientras que la mayoría de los dictámenes más recientes la han aceptado.

A su vez, estas posiciones se han fundamentado de la siguiente forma: 
Por rechazar la potestad, Contraloría General considera que la competencia de las municipalidades es determinada únicamente por el elemento territorio. Se trata de la interpretación clásica y literal de la normativa del ramo.

Por aceptar la potestad, Contraloría General ha esgrimido tres tipos de argumentos: i) citar normativa especial que faculte expresamente a las municipalidades a actuar en otros territorios, sea establecida en su ley orgánica o en otra normativa especial (dictámenes 51.620, de 2005 y 3.000, de 2017); ii) cuando la actuación sea ejecutada dando cumplimiento a sus atribuciones y reforzando sus funciones municipales, como promover el desarrollo comunitario, la asistencia social y educación de sus propios habitantes, mediante actuaciones en territorios diversos. Se trata de la interpretación de lo dispuesto en los artículos 3 y 4 de la Ley Orgánica Constitucional de Municipalidades, como también de la definición de municipalidades contenida en su Ley Orgánica y en la Constitución Política, por la cual el elemento materia otorga competencia al beneficiar a la población local (dictámenes 66.754, de 2013, y 38.520, de 200o); iii) que no se estén desempeñando funciones que correspondan a otras municipalidades ni a otros órganos de la Administración del Estado (dictamen 2.772, de 2017, fundado en los dictámenes 51.620, de 2005, y 66.754, de 2013).

Es de especial atención este segundo argumento reconocido por Contraloría General, puesto que es la existencia de un segundo factor de competencia basado en un criterio de interpretación finalista, por el cual las municipalidades también tienen un mandato constitucional y legal expreso de satisfacer las necesidades de los habitantes de la comuna, necesidades las cuales desde luego pueden exceder el territorio físico, lo cual faculta a las municipalidades a ejecutar actos fuera de la comuna, siempre y cuando beneficien a su población.

En este sentido, en nuestra cultura los municipios son verdaderamente la entidad más próxima al ciudadano (Cea Egaña, 2016: 219), por lo cual en buena medida son los órganos que otorgan beneficios que en la práctica no son proveídos por la Administración central. De este modo, el inciso tercero del citado artículo 118 y el artículo 1 de su Ley Orgánica definen a las municipalidades según su finalidad de beneficiar a los habitantes. Es así como por definición estos son los órganos «cuya finalidad es satisfacer las necesidades de la comunidad local y asegurar su participación en el progreso económico, social y cultural de la comuna». Además, desde luego que el inciso cuarto del artículo 1 de la Constitución es aplicable, pues está el Estado al servicio de la persona humana, y muchas de las funciones y atribuciones establecidas en su Ley Orgánica y demás leyes relacionadas se refieren a la población, y no así al territorio.

Finalmente, los dictámenes 51.620/2005, 22.772/2017 y 66.754/2013 merecen ser especialmente destacados, por tres razones.

En primer lugar, el Dictamen 51.620/2005 es citado por buena parte de la jurisprudencia administrativa como fundamento a utilizar únicamente el elemento territorio, no obstante que acto seguido a dicha argumentación ese propio dictamen es el que provee los argumentos posteriores por los cuales una municipalidad puede actuar fuera de su territorio. Por tanto, en dictámenes posteriores dicho Dictamen 51.620/2005 siempre 
ha sido citado de forma incompleta. Es más, la resolución de ese dictamen no es que el municipio solamente pueda actuar dentro de su territorio, sino que obliga a Contraloría General a examinar una actuación fuera del territorio a la luz de argumentos que están a favor de la actuación extraterritorial.

En segundo lugar, debemos resaltar la importancia del Dictamen 22.772/2017, puesto que es el último dictado sobre el particular. Por este motivo, entendemos que la siguiente cita textual es el criterio actual de Contraloría General de la República sobre que las municipalidades puedan actuar válidamente fuera de su territorio:

Sobre el particular, el criterio dispuesto por la jurisprudencia administrativa mediante los dictámenes 51.620, de 2005, y 66.754, de 2013, señala que el territorio marca el límite de la competencia de cada municipalidad, de manera que las funciones y atribuciones que el ordenamiento jurídico les confiere, han sido concebidas para ser ejercidas solamente dentro de su respectivo ámbito territorial, sin ser procedente que un municipio extienda su funcionamiento fuera de éste.

Sin embargo, como señalan los dictámenes referidos, lo anterior no significa que las entidades edilicias estén impedidas de actuar fuera de los límites de la comuna, siendo esto posible, incluso pudiendo adquirir bienes inmuebles ubicados fuera de ella, en la medida que estas actuaciones no impliquen el desempeño de funciones o potestades propias de su naturaleza de organismo público en otras comunas.

En tercer y último lugar, es necesario subrayar la relevancia del Dictamen 66.754/2013 en la actualidad. Desde ya destaca por ser el que cambió la jurisprudencia en Chile, puesto que anterior a él existían seis dictámenes que rechazaban toda facultad de los municipios fuera de su territorio en comparación a dos que la acogían, además de que Contraloría General había rechazado esta facultad durante ocho años y en cuatro dictámenes seguidos, mientras que con el Dictamen 66.754/2013 en la actualidad tres de cada cuatro asuntos han sido acogidos. Y, a mayor abundamiento, dicho dictamen es el principal fundamento del último que haya sido dictado a la fecha, 22.772/2017, el cual resolvió acoger esta facultad y con un criterio amplio, referido a que las actuaciones de las municipalidades fuera de su territorio son válidas siempre y cuando no conlleven desempeñar funciones o potestades propias de otros órganos públicos.

\section{Caso del Centro de Alto Rendimiento de Estudiantes de Salamanca}

El 8 de febrero de 2012, la Municipalidad de Salamanca suscribió un contrato de arrendamiento de inmueble en la ciudad de Viña del Mar, con el fin de que fuere destinado como hogar estudiantil gratuito para los estudiantes destacados y de escasos recursos provenientes de su comuna, mientras cursen estudios superiores y acrediten buen rendimiento académico. Esta prestación forma parte del programa de Centros de Alto Rendimiento para Estudiantes de Salamanca (CARES), el cual data de 2010 y continua en la actualidad en diversas ciudades del país. 


\section{Los argumentos de Contraloría Regional de Coquimbo}

Posteriormente, a propósito de una denuncia sobre pagos irregulares a funcionarios, la Contraloría Regional de Coquimbo emitió el Informe de Investigación Especial 19/2012, del 23 de octubre de 2012, en que, fundado en los dictámenes 27.208/1989 y $3.289 / 1994$, expone y resuelve lo siguiente:

En relación a la materia, cabe nuevamente recordar que las competencias de las municipalidades están determinadas por la materia, que son las funciones y atribuciones a que se encuentran abocadas a fin de dar cumplimiento a sus objetivos y por el territorio, que es el ámbito espacial dentro del cual cada municipio ejerce sus funciones y atribuciones, esto es la comuna, de donde se desprende que este es el elemento que permite diferenciar a un municipio de otro, ya que las funciones y atribuciones son las mismas para todos ellos.

De esta manera, en mérito de lo expuesto y de los antecedentes tenidos a la vista en esta ocasión, no es posible advertir que el inmueble tomado en arrendamiento en la comuna de Viña del Mar, se enmarca en las funciones asignadas a los municipios en su Ley Orgánica y a los criterios contenidos en la jurisprudencia administrativa del Órgano Contralor. ${ }^{3}$

[...] En relación con el CARES ubicado en la comuna de Viña del Mar y a la contratación de doña Karen Jarufe Sturla para la administración del mismo, con recursos del Departamento de Educación, cabe señalar que no procede que el municipio arriende un inmueble y disponga la contratación de personal para su administración en territorio distinto a la jurisdicción, por cuanto no existe disposición alguna que lo faculte para hacerlo. ${ }^{4}$

\section{Los argumentos de la Municipalidad de Salamanca}

El 31 de mayo de 2013, la Municipalidad de Salamanca solicita pronunciamiento y dictamen a la Contraloría General de la República. En esta presentación, redactada por el suscrito, se argumentó que el municipio sostiene que las actuaciones objetadas se enmarcan dentro de un programa tendiente a promover el desarrollo comunitario, a través de la habilitación de un hogar estudiantil que beneficie a sus alumnos destacados y de escasos recursos. De este modo, el municipio expone que el objetivo de dicho beneficio es que los alumnos destacados de la comuna puedan estudiar una profesión u oficio, ya que sin esta ayuda les sería imposible. En la comuna no existen establecimientos de educación superior, y los habitantes de la localidad carecen de los recursos necesarios para sustentar por sí solos el alojamiento en regiones de sus hijos. La comuna de Salamanca se encuentra alejada de las grandes ciudades del país, posee 24.492 habitantes, de los cuales el $51,8 \%$ vive en zona urbana y $48,2 \%$ en zonas rurales, y es

3. «Informe de investigación especial: Municipalidad de Salamanca, región de Coquimbo», Contraloría Regional de Coquimbo, 23 de octubre de 2012, p. 5, disponible en https://bit.ly/2XTpDsw.

4. «Informe de investigación especial», p. 7. 
poblada mayoritariamente por gente de escasos recursos. A modo de ejemplo, en la comuna no existen colegios privados. ${ }^{5}$

Segundo, en cuanto al derecho, el municipio arguye que el factor de competencia de las municipalidades no es únicamente el territorio, sino que también puede serlo su finalidad (elemento materia), la cual es satisfacer las necesidades de la comunidad local y asegurar su participación en el progreso económico, social y cultural. Así se establece expresamente tanto en los artículos 118 y 121 de la Constitución Política de la República, como en los artículos 3 letra c) y artículo 4 letra a) de la Ley Orgánica Constitucional de Municipalidades, a propósito de sus funciones. Además, en cuanto a los dictámenes citados, el municipio expone que el Dictamen 51.620/2005 no fue considerado por Contraloría Regional, decisión en la cual Contraloría General reconoció la posibilidad de ejecutar actuaciones extraterritoriales, siempre que no se afecte la competencia de otros organismos públicos, supuesto que se verifica en la especie.

En definitiva, el municipio alega que existe una colisión entre dos principios esenciales, que son el territorio en su sentido estricto y los fines municipales. Estos son los factores de competencia posibles, aportando que los fines municipales son un segundo factor de competencia, y arguyendo que en el presente caso deben primar los fines municipales.

\section{La decisión de Contraloría General de la República}

Dicho lo anterior, la Contraloría General de la República se pronunció sobre el particular en el Dictamen 66.754/2013, decidiendo en los siguientes términos:

Ahora bien, efectuado un nuevo análisis de los antecedentes tenidos a la vista, es posible advertir que en el inmueble arrendado por el municipio de que se trata, se da alojamiento temporal a ciertos estudiantes de la comuna de Salamanca, durante el respectivo año académico de los cursos a los que se asisten en establecimientos de educación superior, ubicados en las ciudades de Viña del Mar y Valparaíso, lo que se enmarca en un programa que, precisamente, busca prestar asistencia social a familias de escasos recursos y propender al desarrollo educacional de la población de Salamanca, contribuyendo a crear condiciones que permitan a sus habitantes la mayor realización espiritual y material posible, dando eficacia a la citada preceptiva constitucional y legal, contemplada en los artículos 1, inciso cuarto, y 19, numeral 10, de la Constitución Política.

Luego, acorde con el criterio contenido en el Dictamen 38.520, de 2000, es menester señalar que no se aprecia inconveniente en la ejecución de acciones, como las que aquí se examinan, en una comuna diferente de la que provienen sus destinatarios, pues, por una parte, con dicha actuación se están reforzando las funciones municipales desarrollo comunitario, asistencia social, educación- y, por otra, el beneficio cuya obtención motiva la aplicación del proyecto respectivo se radica, en definitiva, en la localidad en que se aprobó la iniciativa.

5. «Reportes estadísticos comunales, comuna de Salamanca», Biblioteca del Congreso Nacional de Chile, disponible en http://bit.ly/2XseRF5. 
En consecuencia, de conformidad con lo expuesto precedentemente, la instalación del mentado hogar estudiantil, por parte de la Municipalidad de Salamanca, se ajusta a derecho.

\section{Comentarios sobre el Dictamen 66.754/2013}

De conformidad con lo expuesto, la Contraloría General de la República tuvo dos grandes opciones para resolver sobre el límite de la competencia municipal. En primer lugar, seguir el argumento presentado por la Contraloría Regional de Coquimbo, sobre que la competencia estaría dada exclusivamente por el elemento territorio, entendido como ejecutar actos dentro del espacio físico denominado comuna. En segundo lugar, seguir el argumento presentado por la Municipalidad de Salamanca y redactado por el suscrito, del tenor de que el municipio también tiene competencia para actuar fuera de su territorio, en el caso de que estos actos extraterritoriales satisfagan las necesidades de su comunidad local. En su Dictamen 66.754/2013, Contraloría General resolvió acoger esta segunda opción. Esto es, atendido que el programa beneficia a los habitantes de la comuna y por tanto al desarrollar este programa el municipio cumple con su función de promover el desarrollo educativo, entonces se aplica el elemento materia o función, que le otorga competencia al municipio para actuar en comunas diversas.

Concretamente, sin este programa los estudiantes de toda una comuna no tendrían acceso a cursar estudios superiores, y la única forma de desarrollar este programa que beneficia a una localidad es que un municipio actúe válidamente fuera de su territorio. Y, como considerare Contraloría General expresamente en esta decisión, el Estado está al servicio de la persona humana, su finalidad es promover el bien común, debe contribuir a crear las condiciones sociales que permitan a todos y a cada uno de los integrantes de la comunidad nacional su mayor realización espiritual y material posible, reconoce el derecho a la educación y le corresponde fomentar el desarrollo de la educación en todos sus niveles, según lo establecido por la Carta Fundamental en sus artículos 1 inciso cuarto y 19 numeral 10.

Finalmente, esta decisión de Contraloría General de la República reviste de importancia en nuestro sistema jurídico por tres razones.

En primer lugar, como fue señalado, el Dictamen 66.754/2013 cambió la jurisprudencia chilena sobre la competencia extraterritorial de las municipalidades. De esta forma, con anterioridad a su dictación Contraloría General había optado históricamente por rechazar esta facultad, en cambio desde su dictación esta atribución ha sido mayoritariamente aceptada. A mayor abundamiento, el comentado dictamen es el fundamento principal de la última decisión sobre el particular, 22.772/2017, que resolvió acoger esta facultad y con un criterio amplio, expresamente validando las actuaciones municipales fuera de su territorio siempre y cuando no conlleven el desempeño de funciones o potestades propias de otros órganos públicos. En suma, fundado en ambas decisiones, en la actualidad un municipio puede tener excepcionalmente competencia para actuar fuera de su territorio, en cumplimiento de sus finalidades y sin invadir las potestades del municipio local. 
En segundo lugar, el dictamen es la decisión mayormente fundamentada sobre este particular, por lo cual es útil para estudiar esta materia. En este sentido, en la decisión se expuso la historia que ha tenido esta discusión, y cita diversos otros dictámenes que fueron ya analizados y que resolvieron en ambas vías, a saber: dictámenes 27.208, de $1989 ; 3.289$, de $1994 ; 38.520$, de 2000 y 51.620 , de 2005.

Por último, esta decisión también cambió en particular la jurisprudencia sobre hogares universitarios. En este sentido, la decisión cita y reconsidera el dictamen 42.608/1994, que en lo atingente se refiere a que Contraloría General de la República tenía un criterio distinto previo al Dictamen 66.754/2013. De este modo, en su primer dictamen, Contraloría resolvió que las municipalidades «no están facultadas para arrendar inmueble y destinarlo a hogar de universitarios de escasos recursos de la comuna». Esto es por cuanto, si bien el artículo 4 de la Ley Orgánica Constitucional de Municipalidades les permite desarrollar funciones relacionadas con la asistencia social, ellas «deben entenderse referidas solo a procurar los medios indispensables para paliar las dificultades de quienes carecen de los elementos esenciales de subsistencia, o sea, se encuentran en estado de indigencia, características que no poseen los beneficios que se proyecta otorgar». Señalado lo anterior, dicho criterio ya no es aplicable en nuestro país, en función de que fue modificado por el Dictamen 66.754/2013. En la actualidad, las municipalidades sí pueden arrendar inmuebles para destinarlo a hogares de universitarios de escasos recursos de la comuna, como acontece en el caso de CARES, el cual, además, faculta el arriendo en distintas localidades que donde se emplace la comuna.

\section{Conclusiones}

De conformidad con lo resuelto en reiteradas ocasiones por Contraloría General de la República, y contrario a la doctrina nacional, el elemento territorio no es necesariamente el único factor o criterio que determina la competencia de las municipalidades.

En la actualidad existen dos interpretaciones y diversos tipos de argumentos, mediante los cuales el abogado litigante puede argumentar las tesis sobre acoger o rechazar que los municipios puedan actuar fuera de su territorio. A favor de estas actuaciones tenemos la existencia de normativa especial, reforzar sus propias funciones municipales al beneficiar a la población local mediante actuar en territorio diverso, y que se estimare que a lo menos el municipio no esté desempeñando funciones propias de otras municipalidades ni de otros órganos de la Administración del Estado. Por la negativa, tenemos la interpretación restrictiva de la doctrina clásica, según la cual las municipalidades únicamente tienen un territorio asignado.

En particular, el argumento más destacable que ha sido acogido por el órgano de control es el que permite acoger la actuación extraterritorial en razón de dar cumplimiento a la función de satisfacer las necesidades de la comunidad local, siempre y cuando no implique infringir las atribuciones de otros órganos. Esto es, atendido que dicho argumento no requiere de normativa especial ni de la concurrencia de circunstancias particulares, sino que siempre que cumpla con ambos requisitos entonces podrá actuar 
válidamente fuera de su territorio. En razón de lo anterior, el presente artículo comenta detalladamente el Dictamen de Contraloría General de la República 66.754/2013, que en definitiva resuelve la validez de la instalación de hogares estudiantiles por parte de municipalidades, en territorios distintos que los que administran por mandato constitucional y legal. El fundamento de la decisión fue precisamente el cumplimiento de las funciones municipales, en los términos señalados. Idéntico criterio es utilizado en el último dictamen sobre esta materia, Dictamen 22.772/2017, el cual a su vez se funda en el ya citado Dictamen 66.754/2013.

\section{Referencias}

Bernaschina González, Mario (1952). Derecho municipal chileno. Tomo 1. Santiago: Jurídica de Chile.

Cea Egaña, José Luís (2008). Derecho constitucional chileno. Tomo 1. Santiago: Ediciones UC.

-. (2016). Derecho constitucional chileno. Tomo 4. Santiago: Ediciones UC.

Fernández Richard, José (2007). Derecho municipal chileno. Santiago: Jurídica de Chile.

GarCíA DE ENTERría, Eduardo y Tomás Ramón Fernández (2002). Curso de derecho administrativo. Tomo 1. Madrid: Civitas.

Pantoja BAUzÁ, Rolando (1998). La organización administrativa del Estado. Santiago: Jurídica de Chile.

Silva Bascuñán, Alejandro (2004). Tratado de derecho constitucional. tomo 10. Santiago: Jurídica de Chile.

Verdugo Marinkovic, Mario, Emilio Pfeffer Urquiaga y Humberto Nogueira Alcalá (1999). Derecho Constitucional. Tomo 2. Santiago: Jurídica de Chile.

ZÚÑIga URbINA, Francisco (2012). «Comentario a la sentencia del Tribunal Constitucional, sobre requerimiento de inaplicabilidad por inconstitucionalidad de los artículos 5 letra c) y 12 del Decreto con Fuerza de Ley 1/2006 del Ministerio del Interior, que fija el texto refundido, coordinado y sistematizado de la Ley 18.695, Orgánica Constitucional de Municipalidades, y de los artículos 15, 124 inciso primero y 221 del Decreto con Fuerza de Ley 4/20.018, de 2006, del Ministerio de Economía, Fomento y Reconstrucción, que fija el texto refundido, coordinado y sistematizado del Decreto con Fuerza de Ley 1, de Minería, de 1982, Ley General de Servicios Eléctricos. Dictada con fecha 15 de marzo de 2012, causa rol 1.669-2010». Gaceta Jurídica, 381: 7-22.

\section{Sobre el autor}

JuAn ANDrÉs Encina Brevis es abogado y licenciado en Ciencias Jurídicas y Sociales de la Universidad de Chile. Miembro del Instituto Chileno de Derecho Administrativo. Asesor externo de municipalidades desde 2007. Su correo electrónico es jaencina@zce. cl. (D) http://orcid.org/0000-0002-0407-0255. 